\title{
Case Report \\ Peripheral Giant Cell Granuloma Associated with a Dental Implant: A Case Report and Review of the Literature
}

\author{
Amy Louise Brown, ${ }^{1}$ Paulo Camargo de Moraes, ${ }^{2}$ Marcelo Sperandio, ${ }^{1}$ \\ Andresa Borges Soares, ${ }^{1}$ Vera Cavalcanti Araújo, ${ }^{1}$ and Fabrício Passador-Santos ${ }^{1}$ \\ ${ }^{1}$ Department of Pathology, São Leopoldo Mandic Institute and Research Centre, 13045-755 Campinas, SP, Brazil \\ ${ }^{2}$ Department of Oral Medicine and Oral Surgery, São Leopoldo Mandic Institute and Research Centre, 13045-755 Campinas, SP, Brazil
}

Correspondence should be addressed to Amy Louise Brown; amy.l.brown@doctors.org.uk

Received 18 December 2014; Accepted 4 March 2015

Academic Editor: Tommaso Lombardi

Copyright (C) 2015 Amy Louise Brown et al. This is an open access article distributed under the Creative Commons Attribution License, which permits unrestricted use, distribution, and reproduction in any medium, provided the original work is properly cited.

The peripheral giant cell granuloma (PGCG) is a nonneoplastic lesion commonly caused by local irritation. This report describes a 46-year-old Caucasian male who presented with a PGCG associated with a dental implant. The dental implant was originally placed in August 2012. Ten months later, the patient presented with a well-circumscribed lesion associated with and covering the implant, at which time the lesion was excised. Four months later, due to recurrence of the lesion, a deeper and wider excisional biopsy with curettage of the adjacent bone was performed. No evidence of recurrence has been reported after 12 months of followup. Immunohistochemistry, using the antibody CD68, was performed to investigate the origin of the multinucleated giant cells, with their immunophenotype being similar to those of other giant cell lesions, including central giant cell granuloma, foreign-body reactions, and granulomatous reactions to infectious agents.

\section{Introduction}

The peripheral giant cell granuloma (PGCG) is a nonneoplastic lesion, characterized by reactive hyperplasia in the presence of local irritation $[1,2]$, which exhibits microscopic features that closely resemble the central giant cell granuloma (CGCG). In most cases, no causal factor is identified; however, dental calculus, followed by ill-fitting dentures and tooth fracture are the most common [3]. The clinical differential diagnosis of a reactive lesion of the gingiva must include pyogenic granuloma, traumatic fibroma, and peripheral ossifying fibroma.

There is little data in the literature regarding the prevalence of reactive lesions associated with dental implants and whether they develop due to mechanical or biological irritation, with the former being associated with inappropriate implant placement and the latter with poor oral hygiene. The complications that may arise in and around implant sites are numerous and may include dehiscence, mucositis, gingival hyperplasia, and the formation of a biofilm [4-6].
This case report describes a peripheral giant cell granuloma associated with a dental implant and reviews similar cases published in the English literature.

\section{Case Presentation}

A 46-year-old Caucasian male presented to the Department of Implant Dentistry, Faculty of Dentistry, University of São Leopoldo Mandic, Campinas, São Paulo, Brazil, in August 2012, requesting implants for aesthetic and functional purposes. Titamax Ex external hexagon implants (Neodent, Brazil) were placed in the regions of the upper left premolar and the lower left first molar, with their respective healing abutments. In June 2013, the patient presented with a lesion associated with and covering the lower left first molar implant site. Intraoral examination showed a well-circumscribed, pedunculated, painless, purple mass measuring approximately $1 \mathrm{~cm}$, rubbery in consistency. Radiographically, in the lower left molar region, the presence of an implant was observed without evidence of radiographic features that 


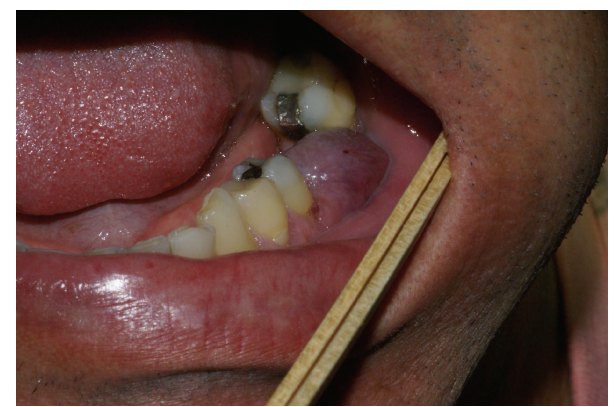

Figure 1: Clinical photograph of the painless purple pedunculated lesion associated with the dental implant.

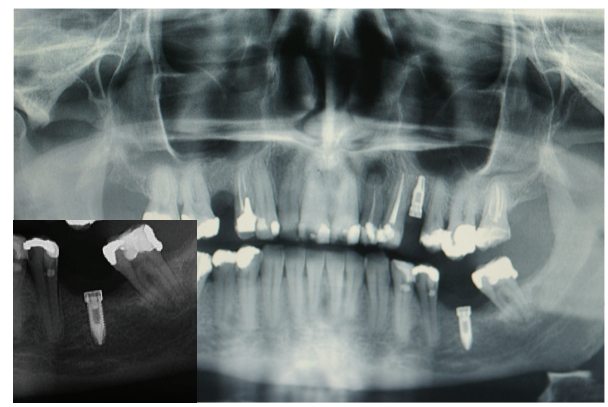

Figure 2: Panoramic radiograph showing the presence of a dental implant in the lower left molar region. Insert: increased magnification focusing on the implant in the region of the lower left molar, showing lack of radiographic features that would be compatible with bone involvement.

would be compatible with bone involvement (Figure 2). The clinical differential diagnosis was pyogenic granuloma and peripheral giant cell granuloma (PGCG) (Figure 1). The patient underwent an excisional biopsy, which was sent to the Department of Oral Pathology, Faculty of Dentistry, University of São Leopoldo Mandic, Campinas, São Paulo, Brazil. The biopsy was fixed in $10 \%$ buffered formalin for 24 hours. Macroscopic examination revealed two fragments of browncolored soft tissue, with a fibrous consistency, the larger fragment measuring $10 \times 8 \times 4 \mathrm{~mm}$ and the smaller fragment $7 \times 6 \times 3 \mathrm{~mm}$. Histopathological examination revealed a fragment of mucosa lined by a parakeratinized stratified squamous epithelium. The lamina propria was composed of connective tissue containing various multinucleated giant cells surrounded by ovoid and spindle-shaped mesenchymal cells with multiple interspersed small blood vessels (Figure 3). The histopathological diagnosis was peripheral giant cell granuloma.

In October 2013, the patient was referred to the Oral Medicine Clinic, Faculty of Dentistry, University of São Leopoldo Mandic, Campinas, São Paulo, Brazil, with a recurrence of the lesion. A deeper and wider excisional biopsy, curettage of the adjacent bone, and application of surgical cement were performed. The biopsy was once again forwarded to the Department of Oral Pathology, Faculty of Dentistry, University of São Leopoldo Mandic, Campinas, São Paulo, Brazil. The histopathological diagnosis was

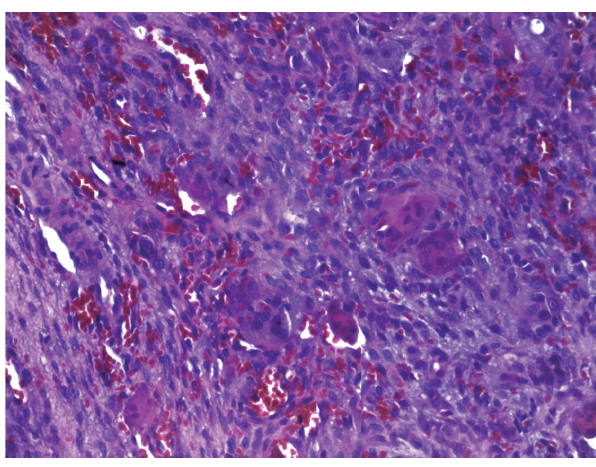

FIGURE 3: Photomicrograph revealing fragments of dense connective tissue, showing proliferation of ovoid and spindle-shaped cells, multinucleated giant cells, and congested blood vessels (haematoxylin and eosin stain, original magnification $\times 200$ ).

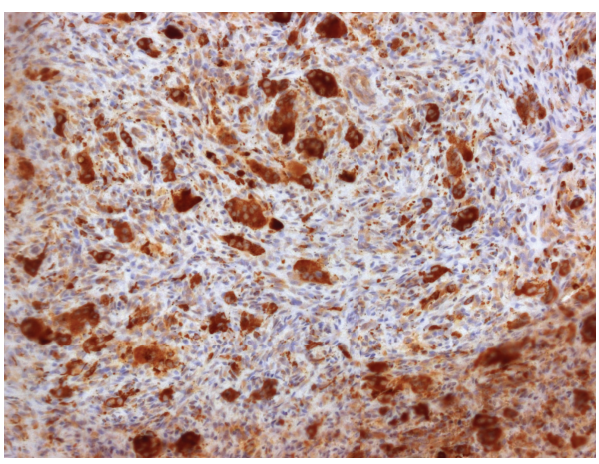

FIGURE 4: Immunohistochemical staining with CD68 showing strong positivity for multinucleated giant cells (original magnification $\times 200$ ).

peripheral giant cell granuloma. The patient remains lesionfree following one year of follow-up.

The paraffin-embedded blocks from each biopsy were selected for immunohistochemical staining using the antibody CD68. Five $\mu \mathrm{m}$ sections were deparaffinized, hydrated, and subsequently immersed in 3\% hydrogen peroxide for 30 minutes (Dinâmica, Diadema, SP, Brazil). For antigen retrieval, the slides were put into a steamer immersed in a citrate buffer ( $\mathrm{pH}$ 6.0) for one hour at $95^{\circ} \mathrm{C}$ (Sigma, St. Louis, MO, USA). The sections were then incubated with the primary antibody overnight at $4^{\circ} \mathrm{C}$ at a dilution of 1:1200 (Dako, Carpinteria, CA, USA). The sections were then incubated with Labeled Streptavidin Biotin (LSAB, Dako, Carpinteria, CA, USA) for 30 minutes, stained for 5 minutes at $37^{\circ} \mathrm{C}$ with $3.3^{\prime}$-diaminobenzidine tetrachloride (Dako, Carpinteria, CA, USA), and counterstained with haematoxylin (Dinâmica, Diadema, SP, Brazil). Macrophages were used as the positive control.

Immunohistochemical staining with CD68 was strongly positive for multinucleated giant cells, as shown in Figure 4, suggesting a histiocyte/macrophage or osteocyte origin. 


\section{Discussion}

When compared with peri-implantitis, reactive lesions associated with dental implants, such as PGCG, are considered rare, with only 12 cases reported in the English literature (Table 1) [5, 7-13].

Dental implants aside, pyogenic granuloma is considered more common than PGCG; it is, therefore, extremely interesting that PGCG is in fact more common than pyogenic granuloma in the dental implant population. A search of the English literature (available for download) revealed 12 cases of PGCG and only five cases of pyogenic granuloma associated with dental implants $[5,6,14-16]$. Hirshberg et al. [7] revealed the presence of PGCG in $12 \%$ of 25 peri-implant soft biopsies examined.

Although the case presented in this study refers to a male patient, our review of the literature revealed that, as PGCG is not associated with dental implants, there is a female preference [1-3, 17], with implant-associated PGCG at a ratio of $1: 1.6$ (male: female). Günhan et al. [18] suggested that this may be due to the influence of sex hormones, with multinucleated giant cells being a target for oestrogen. Immunohistochemical investigation for oestrogen receptors in peripheral and central giant cell lesions of the jaws revealed positivity for the former and negativity for the latter, respectively [19, 20]. However, it may be suggested that in the context of implant-associated PGCG the influence of oestrogen would be less important, owing to the majority of patients being postmenopausal and hence serum levels of oestrogen fall.

In the present review, the age range was noted to be 3174 years, with an average age of 50.9 years, as observed by Katsikeris et al. [21] who described PGCG as most common in patients aged 40 to 60 years. Motamedi et al. and Shadman et al., however, observed a mean age range of 31 and 33 years, respectively $[2,3]$. It is important to highlight that the expected age range and average age may be higher in the implant population.

PGCG has been reported as being more common in the mandible [21], which can be corroborated by the present study, where the posterior mandible was demonstrated as the most common site, featuring eight of the $13(62 \%)$ reported cases. The time lapse between implant placement and initial presentation of PGCG ranged from 3 months to 12 years, with the present case presenting 10 months after implantation. Although, controversial, tooth extraction has been described as an etiological factor for the development of PGCG [21, 22], as demonstrated by Hirshberg et al. [7], who showed that PGCG developed following tooth extraction in 8 to $11 \%$ of PGCG cases examined, appearing up to one year after the procedure. Therefore, it would be interesting to investigate whether the cases shown in Table 1 underwent tooth extraction prior to implant placement and, if so, the time between extraction and implant placement. A review of the literature revealed that dental implant-associated PGCG initially presented as peri-implantitis, loose healing abutments, exophytic masses, and profuse bleeding on toothbrushing. Cloutier et al. suggested that with time the abrasive surface of a dental implant has the capacity to become a source of chronic irritation, which, in some cases, may provoke reactive lesions, such as PGCG and PG [9].

In the cases reviewed, a recurrence rate of $46.2 \%$ was observed, with some lesions reported as recurring five times [11], which is considerably higher than that of PGCG not associated with dental implants, where a recurrence rate of 9.9\% has been reported [22]. However, it is important to highlight that the number of cases reported so far is too small for valid conclusions to be made.

Six of 13 cases recurred, three of which had initially been treated solely with curettage. Only one case was excised from the start, which also recurred. Of the seven cases that were initially excised and curetted, only two recurred. Five of the thirteen cases required surgical removal of the implant (38\%).

Bischof et al. [8] described a PGCG in a 56-year-old female with three implants in the posterior mandible. Despite correct spacing, the angulation of the implants was inappropriate, which led to the healing abutments of two of them to be partially unscrewed and juxtaposed. In addition, the patient described difficulty with performing oral hygiene, due to bleeding; therefore, dental plaque was allowed to accumulate, potentiating the tissue reaction. This corroborates the study by Özden et al. [10], who described a case of PGCG associated with a dental implant that occurred due to a poorly adapted prosthesis, which led to the accumulation of dental plaque and irritation of the gingiva. In the present study, a Titamax Ex external hexagon implant (Neodent, Brazil) was used, which is the material most commonly encountered in dental implants. Wilson Jr. et al. [23] demonstrated, using scanning electron microscopy (SEM) and energy dispersive $\mathrm{X}$-ray spectrometer (EDS), that radiopaque foreign bodies, predominantly titanium and dental cement, surrounded by a chronic inflammatory infiltrate were present in 34 of 36 cases of peri-implantitis biopsied. However, in the present case, where only light microscopy was used, no particles were observed.

The presence of peri-implant metal particles has been reported as being caused by the insertion mechanics, an inadequate abutment placement, and early removal of failing implants [24], all of which may cause a hypersensitivity reaction and subsequent macrophage recruitment. Olmedo et al. [5] demonstrated the presence of free or phagocytosed metallike particles located in the peri-implant soft tissue, which was suggested, may lead to a corrosive process, as shown by Rodrigues et al. [25] in a retrospective study of implant failure following peri-implantitis. Their subsequent study, which reported on a pyogenic granuloma and peripheral giant cell granuloma associated with dental implants, confirmed the presence and absence of particles, likely titanium, for the former and latter lesions, respectively, leading to the suggestion that PGCG associated with dental implants is simply induced by trauma [5].

In terms of treatment, it is important that any exacerbating factors, such as fractured prostheses and restorations, large or poorly adapted restorations, and dental calculus, should be removed. Other factors should also be considered, such as diastema, which can promote retention of food particles, orthodontic appliances, and dental implants. Following removal of the causal factor, the surgical excision of the lesion 


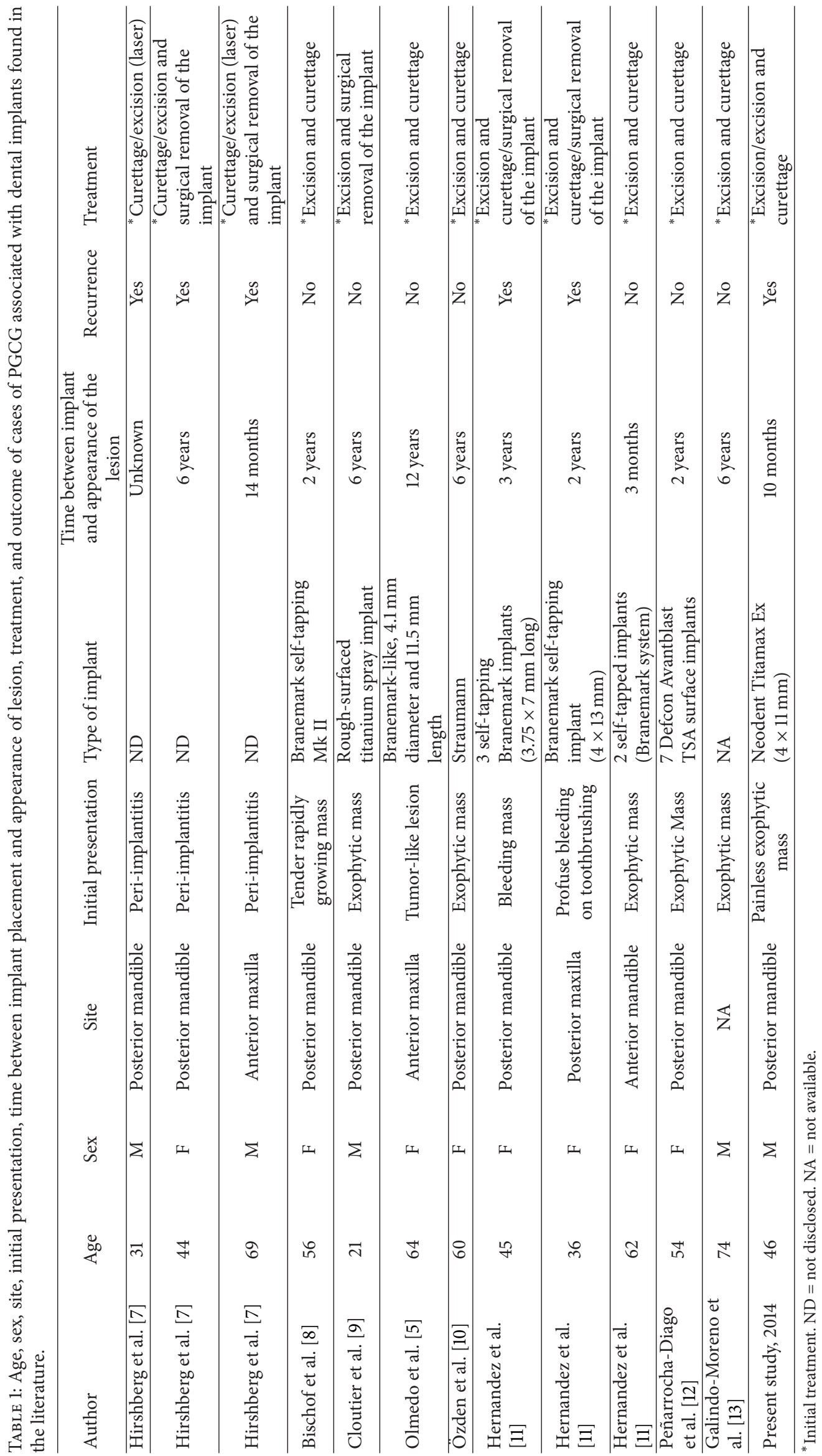


should be performed, associated with debridement of the adjacent bone, which is paramount for the prevention of recurrence [9].

Immunohistochemistry for CD68 was performed in order to confirm the origin of the multinucleated giant cells in the lesion. The literature is controversial in terms of the origin of these multinucleated giant cells, with speculation over a macrophage or osteoclast origin. Various studies have shown that multinucleated giant cells in PGCG demonstrate positivity for the immunohistochemical markers MB-1, vimentin, $\alpha$-1-antichymotrypsin, and CD68, suggesting histiocyte/macrophage or osteoclast origin $[17,26]$. GalindoMoreno et al. recently demonstrated that there is no difference between the immunophenotype of the multinucleated giant cells present in PGCG associated with dental implants, when compared to PGCG, central giant cell granuloma, and peri-implant osteolysis [13].

In conclusion, reactive peri-implant lesions should be removed in their entirety in order to prevent recurrence and implant failure. In addition, clinical experience reveals that differences in opinions exist regarding whether the implant should also be removed during excision of the lesion; therefore, it is critical that these lesions are reported so as to arrive at a treatment consensus. Furthermore, it is paramount that histological examination is performed on all peri-implant soft tissue reactions in order to arrive at an appropriate diagnosis, as other neoplastic and nonneoplastic lesions such as pyogenic granuloma, central giant cell granuloma, the brown tumor of hyperparathyroidism, and malignancy must be excluded [27].

\section{Conflict of Interests}

The authors declare that there is no conflict of interests regarding the publication of this paper.

\section{References}

[1] A. V. Chaparro-Avendaño, L. Berini-Aytés, and C. Gay-Escoda, "Peripheral giant cell granuloma: a report of five cases and review of the literature," Medicina Oral, Patología Oral y Cirugía Bucal, vol. 10, no. 1, pp. 48-57, 2005.

[2] M. H. K. Motamedi, N. Eshghyar, S. M. Jafari et al., "Peripheral and central giant cell granulomas of the jaws: a demographic study," Oral Surgery, Oral Medicine, Oral Pathology, Oral Radiology, vol. 103, no. 6, pp. e39-e43, 2007.

[3] N. Shadman, S. F. Ebrahimi, S. Jafari, and M. Eslami, "Peripheral giant cell granuloma: a review of 123 cases," Dental Research Journal, vol. 6, no. 1, pp. 47-50, 2009.

[4] N. P. Lang, T. G. Wilson, and E. F. Corbet, "Biological complications with dental implants: their prevention, diagnosis and treatment," Clinical Oral Implants Research, vol. 11, pp. 146-155, 2000.

[5] D. G. Olmedo, M. L. Paparella, D. Brandizzi, and R. L. Cabrini, "Reactive lesions of peri-implant mucosa associated with titanium dental implants: a report of 2 cases," International Journal of Oral and Maxillofacial Surgery, vol. 39, no. 5, pp. 503$507,2010$.

[6] I. Dojcinovic, M. Richter, and T. Lombardi, "Occurrence of a pyogenic granuloma in relation to a dental implant," Journal of Oral and Maxillofacial Surgery, vol. 68, no. 8, pp. 1874-1876, 2010.

[7] A. Hirshberg, A. Kozlovsky, D. Schwartz-Arad, O. Mardinger, and I. Kaplan, "Peripheral giant cell granuloma associated with dental implants," Journal of Periodontology, vol. 74, no. 9, pp. 1381-1384, 2003.

[8] M. Bischof, R. Nedir, and T. Lombardi, "Peripheral giant cell granuloma associated with a dental implant," The International Journal of Oral \& Maxillofacial Implants, vol. 19, no. 2, pp. 295299, 2004.

[9] M. Cloutier, M. Charles, R. P. Carmichael, and G. K. B. Sándor, "An analysis of peripheral giant cell granuloma associated with dental implant treatment," Oral Surgery, Oral Medicine, Oral Pathology, Oral Radiology and Endodontology, vol. 103, no. 5, pp. 618-622, 2007.

[10] F. O. Özden, B. OÖzden, M. Kurt, K. Gündüz, and Ö. Günhan, "Peripheral giant cell granuloma associated with dental implants: a rare case report," The International Journal of Oral \& Maxillofacial Implants, vol. 24, no. 6, pp. 1153-1156, 2009.

[11] G. Hernandez, R. M. Lopez-Pintor, J. Torres, and J. C. D. Vicente, "Clinical outcomes of peri-implant peripheral giant cell granuloma: a report of three cases," Journal of Periodontology, vol. 80, no. 7, pp. 1184-1191, 2009.

[12] M. A. Peñarrocha-Diago, J. Cervera-Ballester, L. MaestreFerrin, and D. Peñarrocha-Oltra, "Peripheral giant cell granuloma associated with dental implants: clinical case and literature review," Journal of Oral Implantology, vol. 38, no. 1, pp. 527-532, 2012.

[13] P. Galindo-Moreno, P. Hernández-Cortes, R. Rios, E. SanchezFernández, M. Camara, and F. O’Valle, "Immunophenotype of dental implant-associated peripheral giant cell reparative granuloma in a representative case report," Journal of Oral Implantology, 2013.

[14] Y. H. Kang, J. H. Byun, M. J. Choi et al., "Co-development of pyogenic granuloma and capillary hemangioma on the alveolar ridge associated with a dental implant: a case report," Journal of Medical Case Reports, vol. 16, no. 8, p. 192, 2014.

[15] A. Kaya, F. Ugurlu, B. Basel, and C. B. Senner, "Oral pyogenic granuloma associated with a dental implant treated with an Er:YAG laser: a case report," Journal of Oral Implantology, 2013.

[16] O. A. Etöz, E. Soylu, K. Kiliçl, Ö. Günhan, H. Akcay, and A. Alkan, "A reactive lesion (pyogenic granuloma) associated with dental implant: a case report," Journal of Oral Implantology, vol. 39, no. 6, pp. 733-736, 2013.

[17] Y. R. Carvalho, A. M. Loyola, R. S. Gomez, and V. C. Araújo, "Peripheral giant cell granuloma: an immunohistochemical and ultrastructural study," Oral diseases, vol. 1, no. 1, pp. 20-25, 1995.

[18] M. Günhan, O. Günhan, B. Celasun, M. Mutlu, and H. Bostanci, "Estrogen and progesterone receptors in the peripheral giant cell granulomas of the oral cavity," Journal of Oral Science, vol. 40, no. 2, pp. 57-60, 1998.

[19] S. B. Whitaker and J. E. Bouquot, "Identification and semiquantification of estrogen and progesterone receptors in peripheral giant cell lesions of the jaws," Journal of Periodontology, vol. 65 , no. 3, pp. 280-283, 1994.

[20] S. B. Whitaker and J. E. Bouquot, "Estrogen and progesterone receptor status of central giant cell lesions of the jaws," Oral Surgery, Oral Medicine, Oral Pathology, vol. 77, no. 6, pp. 641644, 1994.

[21] N. Katsikeris, E. Kakarantza-Angelopoulou, and A. P. Angelopoulos, "Peripheral giant cell granuloma. Clinicopathologic 
study of 224 new cases and review of 956 reported cases," International Journal of Oral and Maxillofacial Surgery, vol. 17, no. 2, pp. 94-99, 1988.

[22] A. J. Mighell, P. A. Robinson, and W. J. Hume, "Peripheral giant cell granuloma: a clinical case study of 77 cases from 62 patients, and literature review," Oral Diseases, vol. 1, no. 1, pp. 12-19, 1995.

[23] T. G. Wilson Jr., P. Valderrama, M. Burbano et al., "Foreign bodies associated with peri-implantitis human biopsies," Journal of Periodontology, vol. 86, no. 1, pp. 9-15, 2015.

[24] R. S. Flatebø, A. C. Johannessen, A. G. Grønningsæter et al., "Host response to titanium dental implant placement evaluated in a human oral model," Journal of Periodontology, vol. 77, no. 7, pp. 1201-1210, 2006.

[25] D. C. Rodrigues, P. Valderrama, T. G. Wilson Jr. et al., “Titanium corrosion mechanisms in the oral environment: a retrieval study," Materials, vol. 6, no. 11, pp. 5258-5274, 2013.

[26] J. C. Tiffee and T. B. Aufdemorte, "Markers for macrophage and osteoclast lineages in giant cell lesions of the oral cavity," Journal of Oral and Maxillofacial Surgery, vol. 55, no. 10, pp. 1108-1112, 1997.

[27] A. Hirshberg, A. Shnaiderman-Shapiro, I. Kaplan, and R. Berger, "Metastatic tumours to the oral cavity-pathogenesis and analysis of 673 cases," Oral Oncology, vol. 44, no. 8, pp. 743752, 2008. 


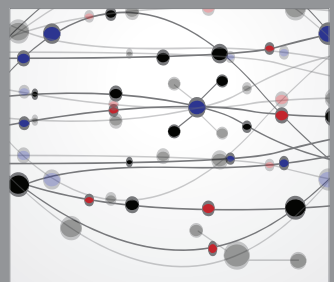

The Scientific World Journal
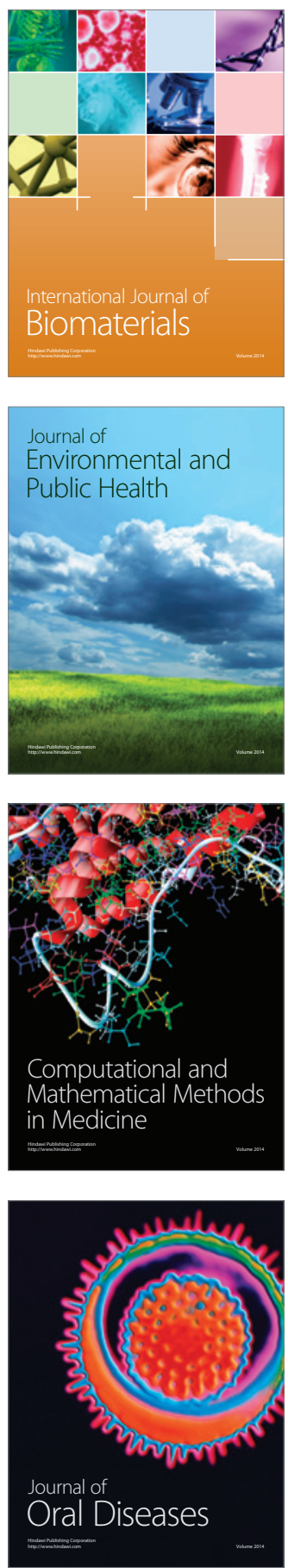
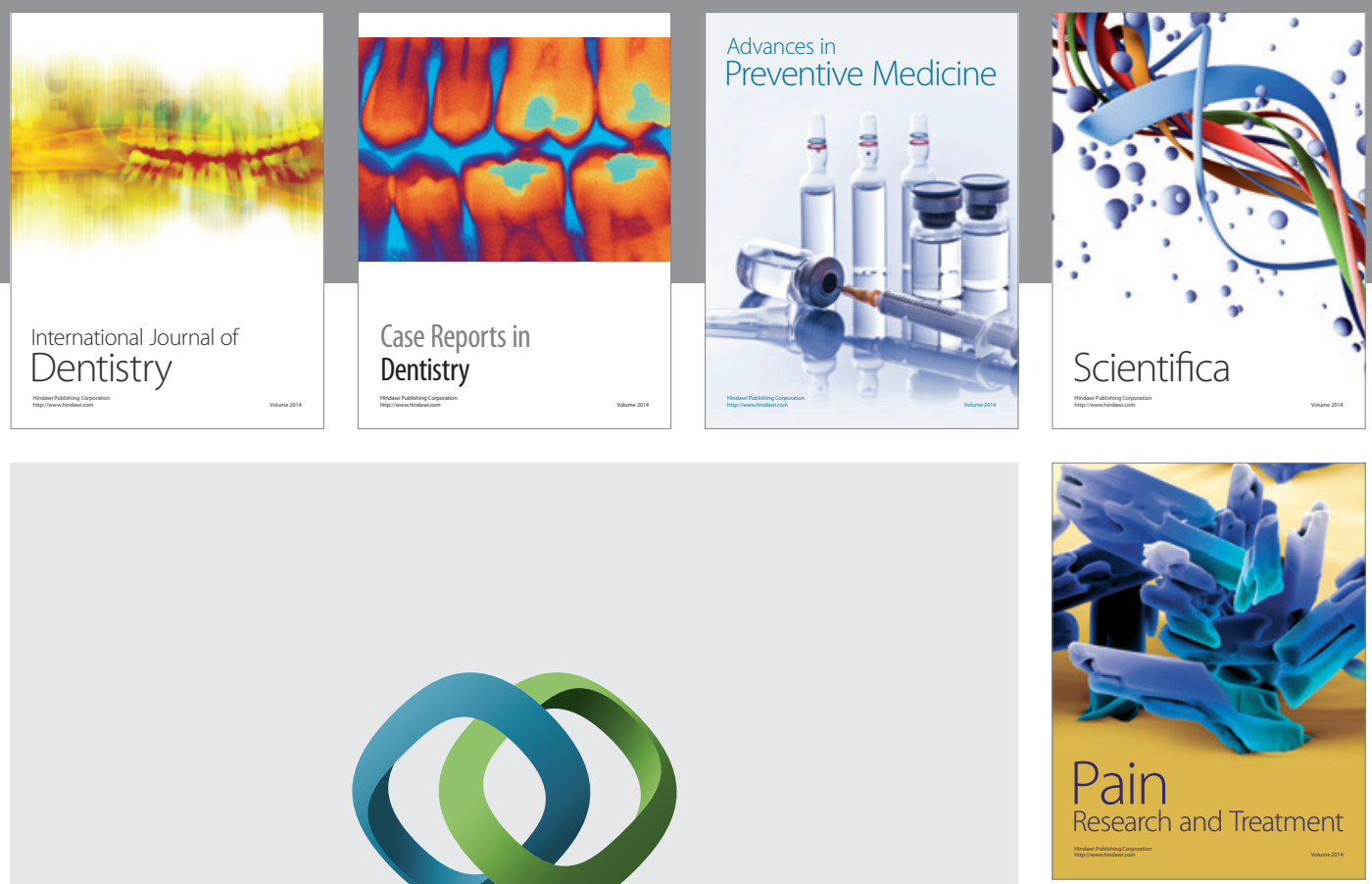

\section{Hindawi}

Submit your manuscripts at

http://www.hindawi.com
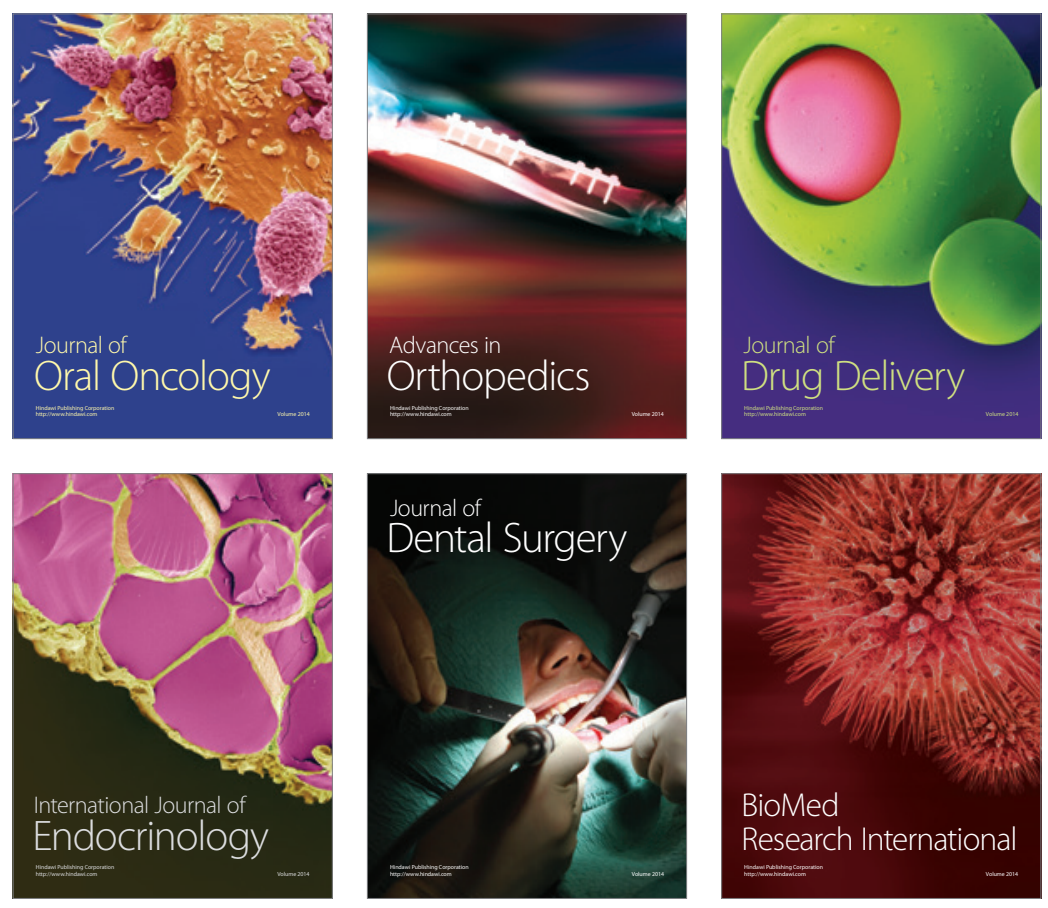

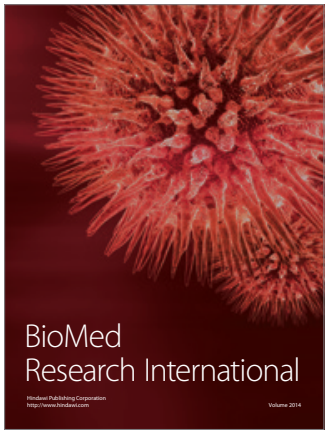

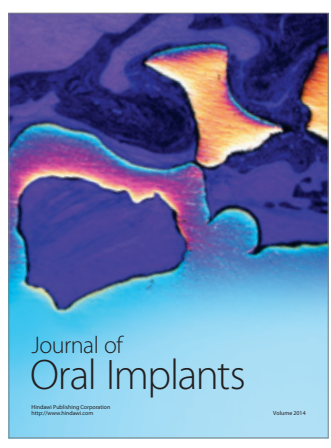
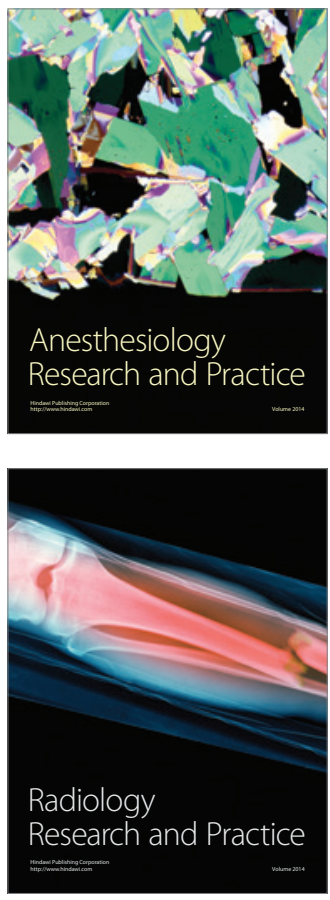